\title{
Is facility based neonatal care in low resource setting keeping pace? A glance at Uganda's National Referral Hospital.
}

\author{
Yaser Abdallah $^{1}$, Flavia Namiiro ${ }^{1}$, Jamir Mugalu ${ }^{1}$, Jolly Nankunda ${ }^{1}$, Yvonne Vaucher ${ }^{2}$, Douglas McMillan ${ }^{3}$
}

1. Department of Paediatrics and Child Health, Makerere University College of Health Sciences.

2. Department of Pediatrics, Division of Neonatal/Perinatal Medicine, School of Medicine, University of California at San Diego, USA.

3. Department of Pediatrics, Dalhousie University and IWK Health Centre, Halifax, Nova Scotia, Canada.

\begin{abstract}
Objectives: To identify reasons for neonatal admission and death with the aim of determining areas needing improvement.

Method: A retrospective chart review was conducted on records for neonates admitted to Mulago National Referral Hospital Special Care Baby Unit (SCBU) from $1^{\text {st }}$ November 2013 to 31 ${ }^{\text {st }}$ January 2014. Final diagnosis was generated after analyzing sequence of clinical course by 2 paediatricians.

Results: A total of 1192 neonates were admitted. Majority 83.3\% were in-born. Main reasons for admissions were prematurity (37.7\%) and low APGAR (27.9\%).Overall mortality was 22.1\% (Out-born 33.6\%; in born 19.8\%). Half (52\%) of these deaths occurred in the first 24 hours of admission. Major contributors to mortality were prematurity with hypothermia and respiratory distress (33.7\%) followed by birth asphyxia with HIE grade III (24.6\%) and presumed sepsis $(8.7 \%)$. Majority of stable at risk neonates 318/330 (i.e. low APGAR or prematurity without comorbidity) survived. Factors independently associated with death included gestational age $<30$ weeks ( $p$ 0.002), birth weight $<1500 \mathrm{~g}$ ( $\mathrm{p} 0.007$ ) and a 5 minute APGAR score of $<7$ (p 0.001$)$. Neither place of birth nor delayed and after hour admissions were independently associated with mortality.

Conclusion and recommendations: Mortality rate in SCBU is high. Prematurity and its complications were major contributors to mortality. The management of hypothermia and respiratory distress needs scaling up. A step down unit for monitoring stable at risk neonates is needed in order to decongest SCBU.

Keywords: Neonatal care, Uganda's National Referral Hospital.

DOI: http://dx.doi.org/10.4314/ahs.v16i2.2

Cite as: Abdallah Y, Namiiro F, Mugalu J, Nankunda J, Vaucher Y, McMillan D. Is facility based neonatal care in low resource setting keeping pace? A glance at Uganda's National Referral Hospital. Afri Health Sci 2016;16(2): 347-355. http:/ / dx.doi.org/10.4314/ahs.v16i2.2
\end{abstract}

\section{Background}

Globally an estimated 6.3 million children under 5 years die annually with $44 \%$ of these deaths occurring during the first month of life ${ }^{1,2}$. Ninety eight percent of the global neonatal deaths occur in developing countries ${ }^{2,3}$. SubSaharan Africa accounts for $39.3 \%$ of all these deaths ${ }^{2}$. Whereas most developing countries have made strides towards reducing under five mortality, further reduction

\section{Corresponding author: \\ Yaser Abdallah, \\ Makerere University \\ College of Health Sciences, \\ P.O Box 7072 Kampala, Uganda \\ Tel: +256712627787, \\ Email: yasam786@hotmail.com}

has become challenging and the slow decline in neonatal mortality rate has been identified as the major obstacle to further reduction of under-five mortality ${ }^{2,4,5}$. Many community based interventions designed to address neonatal mortality in developing countries may have contributed to some decline in neonatal deaths $s^{6}$ but further reduction in neonatal deaths in the developing countries will need scaling up care in health facilities.

In Uganda, neonatal mortality contributes $26 \%$ of underfive mortality. Like most developing countries; decline in neonatal mortality rate in Uganda at 2.2\% per annum has not been significant ${ }^{7}$. With intensive effort in addressing maternal and neonatal mortality in the community ${ }^{6,8}$ there has been an increase in health facility deliveries (57\%) but the total number of neonates dying annually has reduced decimally ${ }^{7,9}$. Previously, global data was used by local poli- 
cy makers in Uganda to develop newborn survival priorities, local data is very crucial but still very scanty ${ }^{7}$.

The Special Care baby Unit (SCBU) of Mulago National Referral Hospital is the busiest neonatal Unit in Ugan$\mathrm{da}$ and largest training unit for doctors and other health workers with respect to neonatal care. Being the busiest neonatal unit it can be used as a model for the other referral units in Uganda. The last study conducted in SCBU to describe outcome of babies was in 1989 when the admission rate was about 133 neonates per month and it revealed neonatal mortality of $18.0 \%{ }^{10}$. Currently the SCBU admits 400 neonates per month yet with respect to space, equipment's and staffing there has been no change. Being a major referral unit, understanding current trend in admission and outcome in SCBU is important in identifying areas that need improvement but equally important in planning facility based newborn care service in Uganda at large.

\section{Method}

\section{Study setting and population}

Mulago National Referral Hospital is situated in Kampala (the capital city of Uganda) serving the urban and peri-urban communities. It is a teaching institution for Makerere University College of Health Sciences and other health training schools. The hospital has over 33,000 births annually.

The Mulago SCBU receives in-born and out-born babies. At full capacity, the unit has 49 cots/incubators plus 6 adult beds for rooming-in (Kangaroo care) but admits sometimes up to thrice its capacity with neonates sharing incubators. Approximately 400 sick babies are admitted every month.

The unit is staffed with 3 paediatricians and 16 nurses. The nurses work in 8 hour shifts and on average each shift has 3 nurses. The unit also has 2 intern doctors and 2- 4 paediatric resident doctors on rotational basis. At night the unit is covered by 2 nurses and 1 intern doctor. The unit has 3 sections (a preterm, term and Kangaroo section) each measuring about $10 \mathrm{x} 6$ meters. The preterm section has 19 incubators and 2 radiant warmers while term section has 20 baby cots and 3 incubators. There is hardly space between incubators and cots. There is no demarcated area for critically ill babies.

The unit functions at level II but receives critically ill neonates in need of advanced respiratory and cardiovascular support. Services offered in the unit include provision of intravenous antibiotics, intravenous fluids mainly as boluses, phototherapy and nasal tube feeding. Maximum respiratory support available is with fixed expiratory valve Continuous Positive Airway Pressure (CPAP) using fisher and pykel setup without heating or blending oxygen and Hudson's nasal prong. Mothers/caregivers feed their babies on a two hourly basis.

Continuous vital monitoring is not readily available. Servo-control temperature regulation for babies is out of reach. CPAP is provided using cold non blended oxygen. Initiation and discontinuation of phototherapy is entirely on clinical grounds. Laboratory guidance of care is seldom used as specimen containers are not readily available, laboratory cannot run all tests and results not given promptly.

\section{Study design, sample selection and data collection}

A retrospective descriptive study was conducted including all neonates admitted to the SCBU of Mulago Hospital in the months of November 2012 to January 2013. All files for neonates admitted during the study period were retrieved from records. All relevant data were captured and missing data noted.

A list of diagnoses / problems was generated (low APGAR score, prematurity, Prematurity + hypothermia, Prematurity + Hypothermia + Respiratory Distress Syndrome (RDS), Prematurity + RDS, Asphyxia + Hypoxic ischemic Encephalopathy (HIE) I, Asphyxia + HIE II, Asphyxia + HIE III, presumed sepsis, Transient Tachypnea of the newborn (TTN), Jaundice, Fever + Dehydration, Hemorrhagic disease of the newborn (HDN), birth defect, birth injury, Meconium aspiration syndrome (MAS), Others). Although some babies might have had more than one problem the most important was considered. For any contradiction in terms of diagnosis two Paediatricians analyzed the sequence of events and determine the most likely final diagnosis.

Term neonates delivered by Caesarean section with respiratory distress that settled within 24 hours were categorized as having TTN. Preterm neonates with distress needing CPAP were categorized as RDS. Term neonates with low 5 minute APGAR Score or stated as low APGAR Score but non-quantified who were encephalopathic (abnormal posture, unconscious, abnormal tone or seizures) were given a diagnosis of asphyxia. Hypoxic 
ischemic Encephalopathy (HIE) was graded according to the Sarnat grading ${ }^{11}$. Term neonates admitted with nonquantified APGAR score but documented as 'low' and who were not encephalopathic were considered as admitted for "low APGAR Score".

Neonates admitted one hour after birth who had indication for admission (APGAR score $<7$ at 5 minutes and Very Low Birth Weight) were labeled as delayed admission. Neonates admitted $>12$ hrs of age who had no initial indication for admission were labeled as $>12 \mathrm{hrs}$ but not delayed. All babies weighing less than $2000 \mathrm{~g}$ had estimated gestational age through New Ballard score ${ }^{12}$.

Admission temperature of $<36.0^{\circ} \mathrm{C}$ was hypothermia. Babies delivered to mothers with offensive liquor, prolonged rupture of membranes $>24 \mathrm{hrs}$, or maternal chorioamnionitis and those febrile with a temperature $>38.0^{\circ} \mathrm{C}$ while not dehydrated were given a diagnosis of presumed sepsis. Babies who were admitted between 5:00 pm and 8:00 am were termed 'after-hours admissions' and those admitted between $8 \mathrm{am}$ and $5 \mathrm{pm}$ were termed 'in-hours' admissions.

\section{Data analysis}

Relevant data of the study population were entered into STATA and imported to SPSS 12.0.1 for analysis. The analysis of patient demographics and baseline outcome variables were summarized using descriptive summary measures: expressed as mean (standard deviation) or median (range) for continuous variables and percent for categorical variables.

All statistical tests were performed using two-sided tests at the 0.05 level of significance. For the regression model, the results were expressed as effect (or odds ratios for binary outcomes), corresponding two-sided 95\% confidence intervals and associated $\mathrm{p}$ values. The $\mathrm{p}$ - values were reported to three decimal places with values less than 0.001 reported as $<0.001$.

Permission was obtained from the hospital management and the institutional ethics review committee to utilize the neonatal records for this study.

\section{Results}

A total of 1192 neonates were admitted between November 2012 and January 2013 (the study period). Their baseline characteristics are shown in Table 1.

\section{Table 1. Baseline characteristics of admitted neonates}

\begin{tabular}{|c|c|}
\hline Characteristics & $\mathbf{N}=1192(\%)$ \\
\hline Sex :Male & $690(57.9)$ \\
\hline Female & $502(42.1)$ \\
\hline Mode of Delivery: Spontaneous vaginal delivery & $784(65.8)$ \\
\hline Caesarean section & $408(34.2)$ \\
\hline Birth Weight (grams): $<1000 \mathrm{~g}$ & $43(3.6)$ \\
\hline $1000-1499 \mathrm{~g}$ & $122(10.2)$ \\
\hline $1500-2500 \mathrm{~g}$ & $361(30.3)$ \\
\hline$>2500 \mathrm{~g}$ & $666(55.9)$ \\
\hline Gestational age (weeks): $\geq 39$ & $519(43.5)$ \\
\hline $37+6-38+6$ & $119(10.0)$ \\
\hline $35-37$ & $200(16.8)$ \\
\hline $30-34+6$ & $283(23.7)$ \\
\hline$<30$ & $71(6.0)$ \\
\hline SGA: yes & $139(11.7)$ \\
\hline No & $1053(88.3)$ \\
\hline Maternal Age: & $197(16.5)$ \\
\hline$\geq 20$ years & $870(73.0)$ \\
\hline Unknown & $125(10.5)$ \\
\hline Maternal HIV Status : Positive & $122(10.2)$ \\
\hline $\begin{array}{l}\text { Negative } \\
\end{array}$ & $661(55.5)$ \\
\hline Unknown & $409(34.3)$ \\
\hline Maternal Parity: & $445(37.3)$ \\
\hline (a) & $527(44.2)$ \\
\hline Unknown & $220(18.5)$ \\
\hline Place of Birth: & $178(14.9)$ \\
\hline Inborn & $993(83.3)$ \\
\hline Home & $21(1.8)$ \\
\hline 5min APGAR: & $358(30.0)$ \\
\hline$<7$ & $712(59.7)$ \\
\hline $\begin{array}{l}\text { Unknown } \\
\end{array}$ & $122(10.3)$ \\
\hline Admission Time: After hour (5pm-8am) & $703(59.0)$ \\
\hline In hour (8am-5pm) & $465(39.0)$ \\
\hline Unknown & $24(2.0)$ \\
\hline Delayed Admission: Yes & $258(21.6)$ \\
\hline No & $729(61.2)$ \\
\hline$>12 \mathrm{hrs}$ but not delayed & $146(12.2)$ \\
\hline Unknown & $59(5.0)$ \\
\hline
\end{tabular}


The mean birth weight of admitted babies was 2508g. Majority of admitted babies were in-born and admit- ted within first hour of birth. Of the 1192 admissions, $703(59 \%)$ occurred later in the day (after 5pm). Table 2 shows diagnosis and place of birth.

Table 2. Diagnosis and place of birth

\begin{tabular}{|c|c|c|c|c|}
\hline Diagnosis & $\begin{array}{l}\text { Health } \\
\text { Center }\end{array}$ & In-born & Home & Total (\%) \\
\hline Low APGAR Score & $7(3.9)$ & $173(96.1)$ & $0(0.0)$ & $180(15.1)$ \\
\hline Prematurity & $29(19.3)$ & $118(78.8)$ & $3(2.0)$ & $150(12.6)$ \\
\hline Prematurity and Hypothermia & $35(25.5)$ & $95(69.3)$ & $7(5.1)$ & $137(11.5)$ \\
\hline Prematurity and RDS & $7(15.7)$ & $38(82.6)$ & $1(2.2)$ & $46(3.9)$ \\
\hline Transient tachypnoea & $9(7.8)$ & $107(92.2)$ & $0(0.0)$ & $116(9.7)$ \\
\hline Prematurity, Hypothermia and RDS & $32(27.6)$ & $76(65.5)$ & $8(6.9)$ & $116(9.7)$ \\
\hline Failure to Feed & $9(8.7)$ & $94(91.3)$ & $0(0.0)$ & $103(8.6)$ \\
\hline Asphyxia and HIE I & $1(3.6)$ & $26(92.9)$ & $1(3.6)$ & $28(2.3)$ \\
\hline Asphyxia and HIEII & $8(15.7)$ & $43(84.3)$ & $0(0.0)$ & $51(4.3)$ \\
\hline Asphyxia and HIE III & $10(13.5)$ & $64(86.5)$ & $0(0.0)$ & $74(6.2)$ \\
\hline Presumed Sepsis & $15(23.4)$ & $49(76.6)$ & $0(0.0)$ & $64(5.4)$ \\
\hline Fever and Dehydration & $1(2.7)$ & $36(97.5)$ & $0(0.0)$ & $37(3.1)$ \\
\hline Birth Defects & $6(28.6)$ & $15(71.4)$ & $0(0.0)$ & $21(1.8)$ \\
\hline Birth Injuries & $0(0.0)$ & $14(100.0)$ & $0(0.0)$ & $14(1.2)$ \\
\hline Jaundice & $0(0.0)$ & $6(100.0)$ & $0(0.0)$ & $6(0.5)$ \\
\hline Hemorrhagic disease of newborn & $2(16.7)$ & $10(83.3)$ & $0(0.0)$ & $12(1.0)$ \\
\hline Seizures & $1(16.6)$ & $5(83.3)$ & $0(0.0)$ & $6(16.2)$ \\
\hline Meconium Aspiration Syndrome & $2(25.0)$ & $6(75.0)$ & $0(0.0)$ & $8(21.6)$ \\
\hline Others & $4(17.4)$ & $18(78.3)$ & $1(4.3)$ & $23(19.3)$ \\
\hline Total & $178(14.9)$ & $993(83.3)$ & $21(1.8)$ & $1192(100.0)$ \\
\hline
\end{tabular}

Neonates admitted with other diagnoses included 8 with intrauterine growth retardation, 3 with anemia, 3 were large babies (weighing $>4.5 \mathrm{kgs}$ ), 2 were admitted okay but following maternal death, 1 for ophpthalmia neonatorum (in-born baby) and 6 had no clear reason in the files for admission.
Overall mortality in the SCBU was $22.1 \%$. Out born babies had mortality of $33.6 \%$ while in-born $19.8 \%$. Majority of deaths $(90 \%)$ occurred within the first week of life with $52 \%$ occurring in the first 24 hours. Fifty six percent $(56.4 \%$ ) of deaths occurred between $5 \mathrm{pm}$ and $8 \mathrm{am}$ (After hours). Table 3 shows bivariate analysis on baseline characteristics and death. 
Table 3. Bivariate analysis on baseline characteristics and death

\begin{tabular}{|c|c|c|c|}
\hline Characteristics & Died $(N=264)$ & OR $(95 \%$ CI $)$ & p-value \\
\hline $\begin{array}{l}\text { Sex } \\
\text { Male } \\
\text { Female }\end{array}$ & $\begin{array}{l}151(21.9) \\
113(22.5)\end{array}$ & $\begin{array}{c}0.96(0.73-1.27) \\
1.04(0.79-1.37)\end{array}$ & 0.797 \\
\hline $\begin{array}{l}\text { Gestational age (weeks) } \\
\geq 39 \\
37+6-38+6 \\
35-37 \\
30-34+6 \\
<30 \\
\end{array}$ & $\begin{array}{l}77(14.9) \\
18(15.1) \\
34(17.0) \\
75(26.5) \\
60(84.5)\end{array}$ & $\begin{array}{c}0.45(0.34-0.61) \\
0.60(0.36-1.01) \\
0.68(0.46-1.01) \\
1.37(1.01-1.87) \\
24.52(12.66-47.56)\end{array}$ & $\begin{array}{l}0.043 \\
0.000 \\
\end{array}$ \\
\hline $\begin{array}{l}\text { Birth weight } \\
<1 \text { OOOg } \\
1 \text { OOO- } 1499 \\
1500-2499 \\
>1=2500 \mathrm{~g} \\
\end{array}$ & $\begin{array}{c}36(83.7) \\
68(55.7) \\
57(15.8) \\
103(15.5)\end{array}$ & $\begin{array}{c}28.11(12.18-64.88) \\
6.88(4.35-10.42) \\
1.11(0.74-1.69) \\
0.69(0.47-1.04)\end{array}$ & $\begin{array}{l}0.000 \\
0.000 \\
0.039\end{array}$ \\
\hline $\begin{array}{l}\text { Small for Gestational Age } \\
\text { No } \\
\text { Yes }\end{array}$ & $\begin{array}{c}237(25.5) \\
27(19.4)\end{array}$ & $\begin{array}{l}1.20(0.77-1.88) \\
0.83(0.53-1.29)\end{array}$ & 0.411 \\
\hline $\begin{array}{l}\text { Maternal Age } \\
<20 \\
>20 \\
\text { Unknown }\end{array}$ & $\begin{array}{l}48(24.4) \\
182(20.9) \\
34(27.2)\end{array}$ & $\begin{array}{l}1.22(0.85-1.75) \\
0.82(0.57-1.18) \\
1.36(0.89-2.07)\end{array}$ & $\begin{array}{l}0.288 \\
0.150 \\
\end{array}$ \\
\hline $\begin{array}{l}\text { Mode of Delivery } \\
\text { Spontaneous Vaginal Delivery } \\
\text { Caesarean Section }\end{array}$ & $\begin{array}{l}198(25.3) \\
66(16.2)\end{array}$ & $\begin{array}{l}1.75(1.29-2.38) \\
0.57(0.42-0.78)\end{array}$ & O.0OO \\
\hline $\begin{array}{l}\text { Maternal HIV Status } \\
\text { Negative } \\
\text { Positive } \\
\text { Unknown }\end{array}$ & $\begin{array}{l}129(19.5) \\
19(15.6) \\
116(28.4)\end{array}$ & $\begin{array}{l}1.31(0.78-2.22) \\
0.76(0.45-1.28) \\
1.28(0.66-2.10)\end{array}$ & 0.307 \\
\hline $\begin{array}{l}\text { Maternal Parity } \\
<1 \\
>1 \\
\text { Unknown }\end{array}$ & $\begin{array}{l}104(23.4) \\
106(20.1) \\
54(24.5)\end{array}$ & $\begin{array}{l}1.21(0.89-1.64) \\
0.83(0.61-1.12) \\
1.18(0.84-1.66)\end{array}$ & $\begin{array}{l}0.219 \\
0.343 \\
\end{array}$ \\
\hline $\begin{array}{l}\text { Place of Birth } \\
\text { Inborn } \\
\text { Health Center } \\
\text { Home }\end{array}$ & $\begin{array}{l}197(19.8) \\
58(32.6) \\
9(42.9)\end{array}$ & $\begin{array}{l}0.49(0.35-0.68) \\
1.90(1.34-2.68) \\
2.69(1.12-6.46)\end{array}$ & $\begin{array}{l}0.000 \\
0.021\end{array}$ \\
\hline $\begin{array}{l}\text { 5min APGAR } \\
\geq 7 \\
<7 \\
\text { Unknown }\end{array}$ & $\begin{array}{l}97(13.6) \\
129(36.0) \\
38(31.1)\end{array}$ & $\begin{array}{l}0.280(0.21-0.38) \\
3.572(2.63-4.84) \\
1.689(1.12-2.54)\end{array}$ & $\begin{array}{l}0.000 \\
0.012\end{array}$ \\
\hline $\begin{array}{l}\text { Admission Time } \\
\text { In hour } \\
\text { After hour } \\
\text { Unknown }\end{array}$ & $\begin{array}{c}112(24.1) \\
149(21.2) \\
3(12.5)\end{array}$ & $\begin{array}{l}1.18(0.89-1.56) \\
0.85(0.64-1.12) \\
0.50(0.15-1.68)\end{array}$ & 0.246 \\
\hline $\begin{array}{l}\text { Admission } \\
\text { Not delayed } \\
\text { Delayed } \\
>12 \text { hours but not delayed } \\
\text { Unknown }\end{array}$ & $\begin{array}{l}144(19.8) \\
96(36.0) \\
12(8.2) \\
15(25.4)\end{array}$ & $\begin{array}{l}2.75(1.48-5.10) \\
6.29(3.31-11.97) \\
0.28(0.15-0.52) \\
1.21(0.66-2.21)\end{array}$ & $\begin{array}{l}0.000 \\
0.000 \\
0.534\end{array}$ \\
\hline
\end{tabular}

Table 4 Bivariate analysis on diagnosis and death

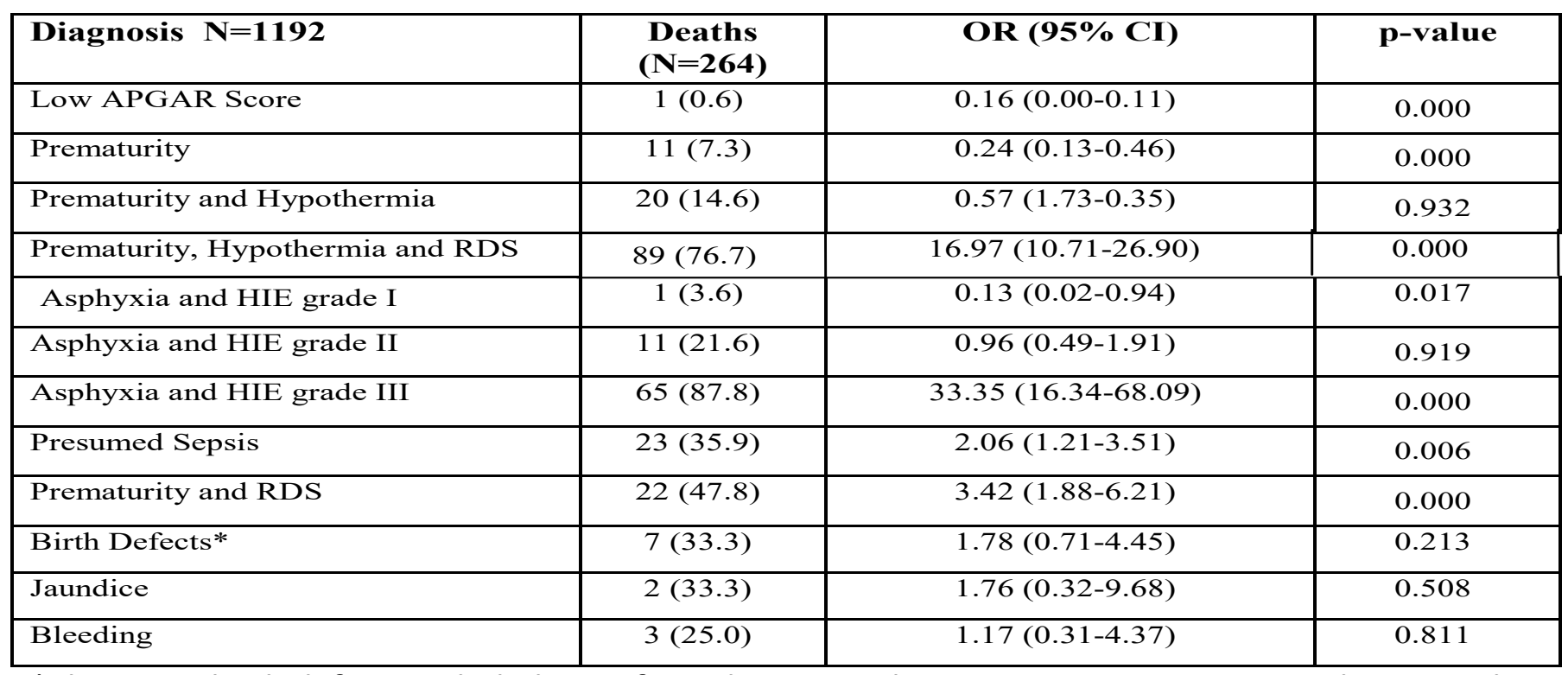

*The seven birth defects included 1 confirmed severe pulmonary stenosis, 4 suspected cyanotic heart disease, 1 hydrocephalus with pulmonary hypoplasia and 1 multiple limb anomalies. 
Nine deaths not included in the bivariate included 3 with meconium aspiration syndrome, 4 neonates admitted without clear reason who died shortly, 1 spontaneous gut perforation and 1 suspected necrotizing enterocolitis.

Table 5 Multivariate regression showing factors independently associated with death

\begin{tabular}{|l|c|c|c|c|c|}
\hline Variables & Odds Ratio & Std. Err. & $\mathbf{z}$ & $\mathbf{P}>\mathbf{z}$ & $\mathbf{9 5 \%}$ CI. \\
\hline Prematurity, Hypothermia \& RDS & 12.19 & 3.85 & 7.90 & $\mathbf{0 . 0 0 0}$ & $\begin{array}{c}6.56 \mathrm{E}+00- \\
2.27 \mathrm{E}+01\end{array}$ \\
\hline Prematurity \& RDS & 5.95 & 2.32 & 4.56 & $\mathbf{0 . 0 0 0}$ & $2.76-12.80$ \\
\hline Asphyxia \& HIEIII & 77.83 & 31.51 & 10.75 & $\mathbf{0 . 0 0 0}$ & $35.19-172.11$ \\
\hline Presumed Sepsis & 11.16 & 3.57 & 7.52 & $\mathbf{0 . 0 0 0}$ & $5.94-20.92$ \\
\hline Health Center Delivery & 1.49 & 0.50 & 1.19 & 0.233 & $0.77-2.87$ \\
\hline Home Delivery & 1.69 & 1.34 & 0.66 & 0.508 & $0.35-8.04$ \\
\hline BWT<1000g & 3.89 & 2.36 & 2.23 & $\mathbf{0 . 0 2 6}$ & $1.18-12.82$ \\
\hline BWT1000-1499g & 2.39 & 0.78 & 2.67 & $\mathbf{0 . 0 0 7}$ & $1.26-4.54$ \\
\hline Vaginal delivery & & & -0.33 & & $0.59-1.44$ \\
\hline Maternal HIV status Unknown & 1.25 & 0.25 & 1.10 & 0.273 & $0.83-1.88$ \\
\hline 5Minute APGAR Score $<7$ & 2.25 & 0.55 & 3.34 & $\mathbf{0 . 0 0 1}$ & $1.39-3.63$ \\
\hline 5Minute APGAR Score Unknown & 0.88 & 0.35 & -0.30 & 0.763 & $0.40-1.94$ \\
\hline Delayed Admission & 1.27 & 0.31 & 0.96 & 0.339 & $0.77-2.07$ \\
\hline Gestational age 30-34+6weeks & 1.68 & 0.48 & 1.81 & 0.070 & $0.95-2.96$ \\
\hline Gestational age <30weeks & 5.32 & 2.89 & 3.07 & $\mathbf{0 . 0 0 2}$ & $1.82-15.46$ \\
\hline
\end{tabular}

\section{Discussion}

The overall mortality of $22.1 \%$ observed in the Mulago SCBU during the three months was higher than that observed in the same unit in the early 90 's ${ }^{10}$ and higher than that observed in the other developing countries ${ }^{13-15}$. This can be attributed to the high number of babies admitted to the Mulago SCBU unit with inadequate services and personnel.

Whereas initiatives to reduce neonatal mortality in the community are being implemented, a concurrent scaling up of care in the health facilities where referrals of difficult cases are envisaged is not taking place. Improvement in public health systems has been highlighted as a necessary component to achieving reduction in neonatal and under 5 mortality $^{16-18}$.
Majority of deaths $(52 \%)$ occurred within the first 24 hours, this finding is similar to that observed in neonatal units in other developing countries ${ }^{3,14,15}$. Out born babies had higher mortality $33.6 \%$ compared to inborn $19.8 \%$, this trend is also similar to that observed in other settings ${ }^{14,15,20}$ but place of birth was not independently associated with mortality. This finding only suggest that place of birth is not the problem but the immediate care babies receive needs to be improved.

Whereas facility newborn care is viewed as necessary in reducing neonatal deaths, factors that have been identified in enabling this to occur included regionalization of perinatal care, strengthening of lower level units, in-born status and adequate nursing staff $f^{19}$. The admission rates to SCBU has almost tripled yet the staffing and facilities have remained same. For SCBU to realize reduction in 
neonatal mortality there is need for more staffing, space and equipment. It is also clear that out-born neonates had higher mortality whether delivered at home or in health facility. This observation calls for strengthening of lower level centers

The main contributors to mortality were prematurity with hypothermia and RDS $33.7 \%$, asphyxia with HIE grade III $24.6 \%$, presumed sepsis $8.7 \%$, prematurity with RDS $8.3 \%$ and prematurity with hypothermia $7.6 \%$. This finding is not in keeping with patterns observed in the unit in early 80 's ${ }^{10}$ and that observed in health facilities in the other developing countries where asphyxia is the main contributor to mortality ${ }^{13-15}$. This observation can be explained by the fact that Mulago SCBU being a tertiary centre has a high preterm birth burden; 449 (37.7\%) of the babies admitted during the study period were preterm and the unit is not well facilitated to handle these numbers.

From the analysis low APGAR score non-quantified without associated encephalopathy was the main indication for admission of babies in to the SCBU (15\%). Although this did not contribute significantly to mortality (OR 0.16); APGAR score $<7$ at 5 minutes was independently associated with mortality with an Odds of 2.23 and $\mathrm{p}>0.001$ in the multivariate analysis. Whereas it is a good practice to admit babies who score poorly at birth ${ }^{21}$ since low APGAR score of less than 7 at 5 minutes has been shown to be associated with asphyxia, poor neurodevelopmental outcome and even death ${ }^{22}$; more objective admission criteria like APGAR score less than 7 at 5 minutes would reduce unnecessary admissions into the Mulago SCBU.

The other main indication for admission of babies into the SCBU was prematurity $(12.6 \%)$ without any other co-morbidity. Admission with diagnosis of prematurity alone was protective against death OR $(0.247 \mathrm{p}>0.00)$. Birth weight of $<1500 \mathrm{~g}$ was a better predictor of mortality than maturity, and odds of death increased with reducing birth weight. This is in keeping with findings from the other centers ${ }^{14,15,20}$. Admitting babies based on birth weight rather than maturity status using $1500 \mathrm{~g}$ and below as an admission criteria would reduce number of babies admitted to the unit.

Although using birth weight of $\leq 1500 \mathrm{~g}$ and APGAR Score of $<7$ at 5 minutes as an admission criteria would reduce admissions to SCBU, a step down level where at risk babies are admitted for close monitoring is essential to ensure that these babies are safely discharged home. This calls for more space, personnel, monitoring equipment and guidelines for discharge or escalation of care.

The third leading indication for admission was prematurity and hypothermia $(11.5 \%)$, this was not associated with mortality (OR 0.568), whereas it is well known that hypothermia is an independent predictor of death, from this data it wasn't the case. This again calls for functional step down level where Kangaroo mother care (KMC) can be instituted promptly with early initiation of breast feeding to prevent hypothermia and SCBU admission among low birth weight stable babies. KMC on low birth weight babies has been associated with reduced morbidity and mortality ${ }^{23}$.

Respiratory distress was the other major indication for admission, TTN $9.7 \%$ and RDS of prematurity $13.6 \%$. RDS of prematurity was significantly associated with death. Prematurity with RDS was associated with death (OR 8.66, p 0.03) while the association between Prematurity with RDS and hypothermia with death was even higher (OR 33, $\mathrm{p}<0.00)$. From this data it is evident that preventing hypothermia should reduce mortality among preterm neonates with RDS. The European guideline on management of RDS in preterm neonates evokes the need for good thermal regulation as necessity in improving outcome of preterm neonates with $\mathrm{RDS}^{24}$. The use of plastic bags at birth and during transportation of preterm babies need be advocated for $^{25}$. More heat sources including radiant warmers and incubators need to be put in place in order to stop the practice of sharing heat source and to encourage servo control thermoregulation for preterm neonates. It is also necessary that oxygen given is heated up as this can be a cause for hypothermia. For these to be instituted more space and personnel are necessary.

Out of 46 babies admitted with prematurity and RDS without hypothermia, $22(47.8 \%)$ died despite receiving CPAP since this was the only intervention available for RDS. It is imperative that SCBU scales up care with respect to RDS care. Advocacy for antenatal steroid and designing protocol on care for RDS including when surfactant should be given is critical. Surfactant is an expensive medicine, it is important for us to appreciate that more than $50 \%$ of these babies survived with just CPAP, so 
clear criteria on who to give surfactant is vital for the unit not to throw away expensive resource and at the same time reduce mortality. There is mounting evidence that early CPAP reduces need for surfactant, mechanical ventilation and broncho pulmonary dysplasia ${ }^{26}$. Provision of fully functional CPAP with capacity to heat and humidify air and using oxygen blenders should help the unit identify babies who qualify for surfactant and those who fail CPAP therapy needing more advanced respiratory support.

Birth asphyxia with grade III HIE was significantly associated with death OR 77.8, $\mathrm{p}<0.00$. It is well known grade III HIE is significantly associated with mortality and morbidity even in highly sophisticated settings ${ }^{27}$. Eight neonates with grade III HIE and 40 with grade II HIE survived but the quality of their life is questionable. These 48 neonates would be categorized as missed opportunity. To improve quality of life of HIE survivors it is necessary that the SCBU develops capacity to provide standard therapeutic hypothermia for these babies ${ }^{28}$. Research is also needed in the field of asphyxia in low resource setting in order to identify cheaper modalities of care.

Presumed sepsis was another major contributor to mortality among neonates admitted to the SCBU, out of 64 babies admitted with diagnosis of presumed sepsis, 23 died. Currently SCBU babies are managed clinically for sepsis. No standard work up is done; choice of antibiotic is based on old studies and text book literature. New study to ascertain pathogens and sensitivity pattern is necessary if deaths from sepsis are to be reduced in the unit.

\section{Conclusion}

Mortality rate in SCBU is high. Prematurity and its complications were major contributors to mortality. The management of hypothermia and respiratory distress needs scaling up. In order to decongest SCBU a revision of admission criteria and a step down unit for monitoring stable at risk neonates is needed.

\section{Study limitations}

This was a retrospective chart review. Some relevant information might have not been captured. Most diagnoses were made on clinical grounds, no investigations were done. Direct cause of death could not be ascertained since investigations were not carried out, and postmortems not done.
What is already known? Major causes of death in low resource settings are asphyxia, prematurity and infection What this study adds: Admission and mortality rates are increasing. It is clear from this study that prematurity with other co-morbidities are the major contributors of death. It is also clear that a good proportion of babies with asphyxia survive.

\section{Contributor ship statement}

Dr. Abdallah Yaser and Dr. Flavia Namiiro did the data entry, literature search and write up. Dr. Jamiru Mugalu, Dr. Jolly Nankunda and Dr. Yvonne Voucher reviewed the methodology and the write up. Mr. Francis Opolot handled the statistical analysis. Dr. Douglas McMillan was involved in interpretation of data and manuscript writing.

\section{Funding}

No funding was obtained from any individual or organization to support this study. Conflict of interest: None of the authors has any conflict of interest to declare.

\section{Data sharing statement}

Data used in this study is in STATA, no data has been used for any other study. This data can be accessed from the primary author.

\section{Acknowledgement}

We would like to thank the Mulago administration for allowing us access this data.

\section{References}

1. Wang H, Liddell CA, Coates MM, Mooney MD, Levitz $\mathrm{CE}$, Schumacher AE, et al. Global, regional, and national levels of neonatal, infant, and under-5 mortality during 1990-2013: a systematic analysis for the Global Burden of Disease Study 2013. Lancet 2014 Sep 13;384(9947):957979 .

2. Liu L, Oza S, Hogan D, Perin J, Rudan I, Lawn JE, et al. Global, regional, and national causes of child mortality in 2000-13, with projections to inform post-2015 priorities: an updated systematic analysis. Lancet 2015 Jan 31;385(9966):430-440.

3. Lawn JE, Cousens S, Zupan J, Lancet Neonatal Survival Steering Team. 4 million neonatal deaths: when? Where? Why? Lancet 2005 Mar 5-11;365(9462):891-900.

4. Bhutta ZA, Chopra M, Axelson H, Berman P, Boerma T, Bryce J, et al. Countdown to 2015 decade report (200010): taking stock of maternal, newborn, and child sur- 
vival. Lancet 2010 Jun 5;375(9730):2032-2044.

5. Lawn JE, Kerber K, Enweronu-Laryea C, Massee Bateman O. Newborn survival in low resource settings--are we delivering? BJOG 2009 Oct;116 Suppl 1:49-59.

6. Lassi ZS, Haider BA, Bhutta ZA. Community-based intervention packages for reducing maternal and neonatal morbidity and mortality and improving neonatal outcomes. Cocbrane Database Syst Rev 2010 Nov 10;(11):CD007754. doi(11):CD007754.

7. Mbonye AK, Sentongo M, Mukasa GK, Byaruhanga R, Sentumbwe-Mugisa O, Waiswa P, et al. Newborn survival in Uganda: a decade of change and future implications. Health Policy Plan 2012 Jul;27Suppl 3:iii104-117.

8. Nalwadda Kayemba C, Naamala Sengendo H, Ssekitooleko J, Kerber K, Kallander K, Waiswa P, et al. Introduction of newborn care within integrated community case management in Uganda. Am J Trop MedHyg 2012 Nov;87(5 Suppl):46-53.

9. UNICEF. Levels and Trends in Child mortality. New York 2015.

10. Mukasa GK. Morbidity and mortality in the Special Care Baby Unit of New Mulago Hospital, Kampala. Ann Trop Paediatr 1992;12(3):289-295.

11. Sarnat H SM. Neonatal encaphalopathy following fetal distress. Arch Neurol 1976(33):697-705.

12. Ballard JL, Khoury JC, Wedig K, Wang L, EilersWalsman BL, Lipp R. New Ballard Score, expanded to include extremely premature infants. J Pediatr 1991 Sep;119(3):417-423.

13. Ayaya SO, Esamai FO, Rotich J, Liechty E. Perinatal mortality in the Special Care Nursery of MoiTeaching and Referral Hospital, Eldoret, Kenya. East Afr MedJ 2004 Nov;81(11):555-561.

14. Ekwochi U, Ndu IK, Nwokoye IC, Ezenwosu OU, Amadi OF, Osuorah D. Pattern of morbidity and mortality of newborns admitted into the sick and special care baby unit of Enugu State University Teaching Hospital, Enugu state. Niger J Clin Pract 2014 May-Jun;17(3):346-351.

15. Klingenberg C, Olomi R, Oneko M, Sam N, Langeland N. Neonatal morbidity and mortality in a Tanzanian tertiary care referral hospital. Ann Trop Paediatr 2003 Dec;23(4):293-299.

16. Farahani M SS. The Effect of Changes in Health Sector Resources on Infant Mortality in the Short-run and the Long-run: A longitudinal econometric analysis. Social Science \& Medicine 2009; 68:1918-1925 PubMed.
17. Fernandes QF, Wagenaar BH , Anselmi L et al. Eff ects of health-system strengthening on under-5, infant, and neonatal mortality: 11-year provincial-level timeseries analyses in Mozambique. Lancet Glob Health 2014; 2:e468-77.

18. Muldoon KA, Galway LP, Nakajima M et al. Health system determinants of infant, child and maternal mortality: A cross-sectional study of UN member countries. Global health 2011;7(42).

19. Neogi SB, Malhotra S, Zodpey S, Mohan P. Does facility based newborn care improve neonatal outcomes? A review of evidence. Indian Pediatr 2012 Aug;49(8):651658.

20. Hedstrom A, Ryman T, Otai C, Nyonyintono J, McAdams RM, Lester D, et al. Demographics, clinical characteristics and neonatal outcomes in a rural Ugandan NICU. BMC Pregnancy Childbirth 2014 Sep 19; 14:3272393-14-327.

21. Ondoa-Onama C, Tumwine JK. Immediate outcome of babies with low Apgar score in MulagoHospital, Uganda. East Afr Med J 2003 Jan;80(1):22-29

22. Vera Ehrenstein. Association of low APGAR scores with death and neurologic disability. Clinical Epidemiology 2009(1):45-53.

23. Conde-Agudelo A, Diaz-Rossello JL. Kangaroo mother care to reduce morbidity and mortality in lowbirthweight infants. Cocbrane Database Syst Rev 2014 Apr 22;4:CD002771.

24. Sweet DG, Carnielli V, Greisen G, Hallman M, Ozek E, Plavka R, et al. European consensus guidelines on the management of neonatal respiratory distress syndrome in preterm infants--2013 update. Neonatology 2013;103(4):353-368.

25. Leadford AE, Warren JB, Manasyan A, Chomba E, Salas AA, Schelonka R, et al. Plastic bags for prevention of hypothermia in preterm and low birth weight infants. Pediatrics 2013 Jul; 132(1):e128-34.

26. Rojas-Reyes MX, Morley CJ, Soll R. Prophylactic versus selective use of surfactant in preventing morbidity and mortality in preterm infants. Cochrane Database Syst Rev 2012 Mar 14; 3:CD000510.

27. Seetha Shankaran. Neonatal encephalopathy: treatment with hypothermia. NeoReviews 2010(11):e85-e92.

28. Jacobs SE, Berg M, Hunt R, Tarnow-Mordi WO, Inder TE, Davis PG. Cooling for newborns with hypoxic ischaemic encephalopathy. Cocbrane Database Syst Rev 2013 Jan 31; 1:CD003311. 